\title{
Prostaglandins and the initiation of blastocyst implantation and decidualization
}

\author{
Thomas G Kennedy ${ }^{1,2}$, Carolina Gillio-Meina ${ }^{1}$ and Sen Han Phang ${ }^{1}$ \\ Departments of ${ }^{1}$ Physiology and Pharmacology and ${ }^{2}$ Obstetrics and Gynaecology, The University of Western Ontario, \\ London, Ontario, N6A 5C1 Canada \\ Correspondence should be addressed to T G Kennedy; Email: tom.kennedy@schulich.uwo.ca
}

\begin{abstract}
The process of blastocyst implantation in mammals is remarkably variable, especially in the extent of trophoblast invasion of the endometrium. In most species studied, the earliest macroscopically identifiable sign of blastocyst implantation is an increase in endometrial vascular permeability in areas adjacent to the blastocysts. This is followed in species with invasive implantation by decidualization, again localized to areas adjacent to the blastocysts. In some species, the application of a stimulus to the endometrium can result in increased endometrial vascular permeability and decidualization. Based initially on studies utilizing inhibitors of prostaglandin (PG) synthesis and more recently on studies using the techniques of transgenics, considerable evidence has accumulated indicating that PGs have an important role in the early events of implantation and artificially induced decidualization. However, which PGs are involved remains controversial. There may be differences between species, and different PGs may be involved at different times. Reproduction (2007) 134 635-643
\end{abstract}

\section{Introduction}

While many different molecules have been implicated in the signaling that occurs between the embryo and the endometrium at the initiation of implantation, this review will concentrate on the role of prostaglandins (PGs). More is known about the role of PGs in implantation in rodents than in other species, and consequently this is the focus. In addition, the involvement of PGs in artificially induced decidualization is reviewed because this reaction has been widely and profitably used as a model of implantation.

\section{Initiation of implantation and decidualization}

Implantation of the embryo involves a complex series of sequential interactions between the embryo and the uterus, beginning with attachment of the blastocyst to the luminal epithelium of the endometrium and ending with the formation of the definitive placenta (see Fig. 1 for the timing of events in the rat). Embryo-endometrial interactions can only be initiated when the embryo and the endometrium have reached a precise stage of maturity; the embryo must be at the blastocyst stage, and hormone-dependent changes leading to the development of a 'receptive' endometrium must have occurred (Psychoyos 1973).

The process of blastocyst implantation in mammals is remarkably variable, especially in the extent of trophoblast invasion of the endometrium. In some species there is little or no invasion of trophoblast cells into the endometrium, whereas in others the invasion is extensive (Psychoyos 1973). In those species with no or limited invasion, the endometrium undergoes little change in response to implantation. By contrast, in those species with extensive invasion, the endometrium undergoes substantial morphological and functional changes referred to as the decidual transformation of the endometrium. In most species, this transformation primarily involves the endometrial stroma and is localized to implantation sites. The fibroblastic stromal cells proliferate and differentiate into decidual cells, which ultimately form the maternal component of the placenta.

In all species investigated - with the exception of humans - there is an increase in the endometrial vascular permeability localized to areas adjacent to the blastocysts (Psychoyos 1973). In mice and rats, this occurs $\sim 4-8 \mathrm{~h}$ after the initial blastocyst attachment, is the first macroscopically identifiable event in implantation, and is commonly taken as defining the beginning of implantation. The increase in endometrial vascular permeability is thought to be an essential prerequisite for decidualization. The localized nature of the endometrial vascular permeability response and subsequent decidualization suggests that they occur in response to interactions between the embryo and the endometrium. 


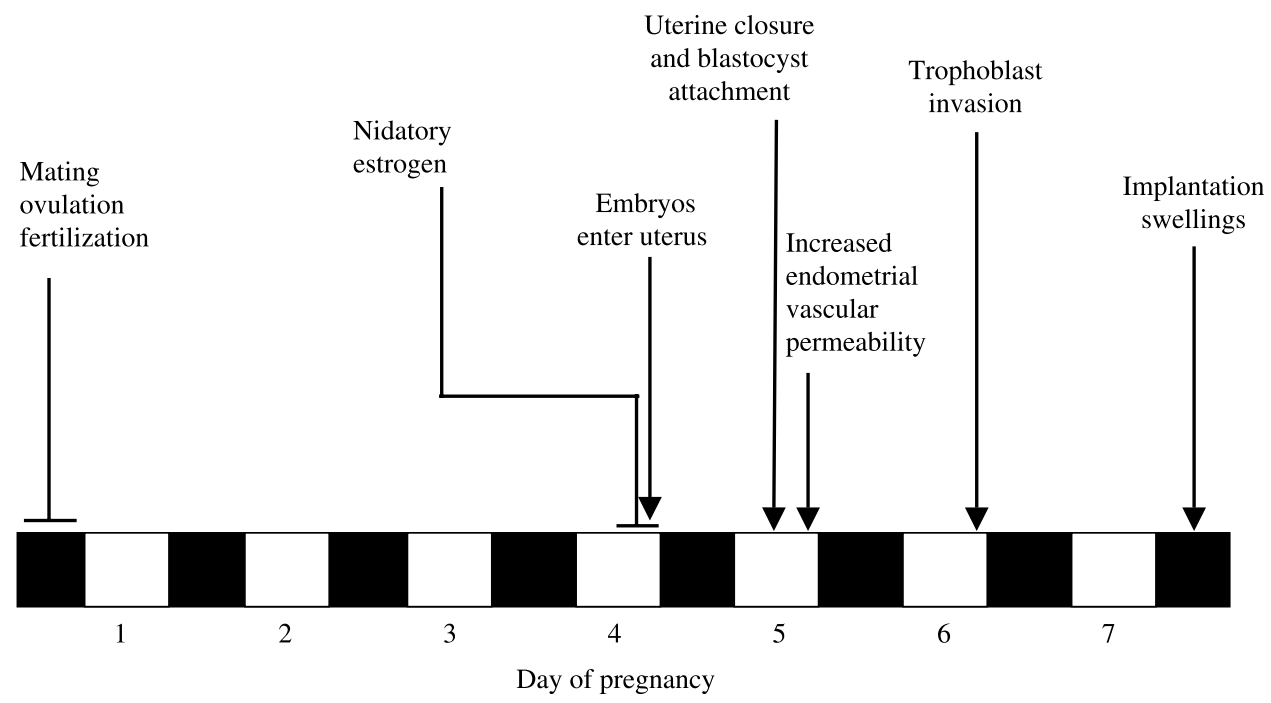

Figure 1 Timing of events occurring early in pregnancy in the rat. For mice, uterine closure and the increased endometrial vascular permeability occur $\sim 18 \mathrm{~h}$ earlier.

\section{Signaling between the embryo and the endometrium}

What is the nature of the signals interchanged between the embryo and the endometrium? Many different molecules have been implicated (for reviews, see Paria et al. 2002, Dey et al. 2004). However, it is possible that the primary signal given by the blastocyst may be physical rather than chemical in nature. The fact that a variety of non-specific stimuli applied to the endometrium of rodents and some other species at an appropriate time will increase endometrial vascular permeability and result in decidualization suggests that the endometrium is able to produce many, if not all, of the signaling molecules involved. In addition, in the human a conceptus does not have to be present to initiate decidualization; it begins 'spontaneously' in the late luteal phase of the menstrual cycle with the differentiation of 'predecidual cells' (Kennedy 2003). An exposure of the endometrium to progesterone beyond the normal nonpregnant luteal phase results in a decidual transformation of the endometrium. Presumably because a signal from the embryo is not required for the initiation of decidualization, the transformation in the human uterus is generalized rather than localized to the site of implantation.

Ultrastructural studies of the early stages of implantation have demonstrated physical interactions between trophoblastic cells of the blastocyst and endometrial luminal epithelial cells. The endometrial vascular permeability response is preceded by interdigitation of microvilli on trophoblastic and epithelial cells, followed by broad areas of apposition of cell membranes (Parkening 1976, Enders \& Schlafke 1979, Segalen \& Chambon 1983). These interactions between the blastocyst and the endometrium are facilitated by the phenomenon of uterine 'closure' which results from the removal of fluid from the uterine lumen in the periimplantation period, thereby bringing the embryo into close contact with the luminal epithelium (Martin et al. 1970, Hedlund et al. 1972, Ljungkvist 1972). The intimate contact between trophoblastic and epithelial cells that results may be sufficient to signal the presence of the blastocyst. Finn \& Porter (1975) have summarized the evidence against the initial signal being physical, but did not take into account the possibility that the blastocyst may have an active role in physically perturbing the luminal epithelium. When cultured in vitro, rat and mouse blastocysts undergo repetitive contractions and dilations (Cole 1967, Bitton-Casimiri et al. 1970, Hurst \& MacFarlane 1981). If these contractions and dilations also occur in vivo, they will presumably amplify the physical signal resulting from the close contact between the blastocyst and the luminal epithelium.

If the initial signal is physical in nature, it will then be necessary for the luminal epithelial cells to convey the signal to the endometrial stroma since it is the stroma that is vascularized and undergoes decidualization. This would require the conversion of the physical signal to a chemical signal by the epithelial cells. In vivo, the luminal epithelium has an essential role in decidualization as indicated by the work of Ferrando \& Nalbandov (1968) and Lejeune et al. (1981), which demonstrated that if the luminal epithelium is destroyed or removed, decidualization cannot be obtained in response to stimuli that would otherwise be deciduogenic. These observations are consistent with the concept that the luminal epithelium responds to natural and artificial deciduogenic stimuli with the production of compounds 
which then result in decidualization. Whether an increase in endometrial vascular permeability can be obtained in the absence of the luminal epithelium is not known.

\section{PG synthesis and action}

PGs are widely produced in mammalian cells from free arachidonic acid (reviewed by Simmons et al. 2004). Arachidonic acid is present mainly in membrane phospholipids and is released from these by the action of phospholipases, principally phospholipase $\mathrm{A}_{2}$. Arachidonic acid can be converted to $\mathrm{PGH}_{2}$ by PG-endoperoxide synthases (PTGSs); there are at least two PTGS isozymes in mammals: PTGS1 and PTGS2. In general, PTGS1 is constitutively expressed, whereas PTGS2 is inducible. $\mathrm{PGH}_{2}$ is converted to the biologically active PGs by specific synthases. Phospholipase $\mathrm{A}_{2}$ and PTGS activities are rate-limiting steps in PG production. The action of PGs is mediated through G-protein-coupled cell-surface receptors, including four subtypes of the PGE receptor (PTGER1, PTGER2, PTGER3, and PTGER4), the PGF receptor (PTGFR), and the $\mathrm{PGI}_{2}$ receptor (PTGIR). In addition, $\mathrm{PGI}_{2}$ may act through the nuclear peroxisome proliferator-activated receptor- $\delta$ (PPARD; vide infra).

\section{PGs and the initiation of implantation/ decidualization}

In general, investigation of the role of PGs in implantation/decidualization can be separated into two phases. In the first, a pharmacological approach was taken, whereas in the second, more recent phase the techniques of transgenics have been used. Both approaches have their limitations. A concern with the pharmacological approach is the specificity of the drugs being utilized. The use of transgenics is largely limited to mice, and there are concerns as to what extent findings in mice are generally applicable.

In retrospect, it is possible to attribute the first indications of the involvement of PGs in implantation to Horan (1971), who reported the effects of a nonsteroidal anti-inflammatory drug on implantation before it had been established that these drugs inhibited PG synthesis. Since then, there have been numerous reports that non-steroidal anti-inflammatory drugs such as indomethacin delay or inhibit the localized increase in endometrial vascular permeability and implantation in a variety of species (reviewed by Kennedy 1990, 1994). Further evidence for the involvement of PGs in implantation was provided by observations demonstrating that the intrauterine administration of $\mathrm{PG}$ antagonists at the expected time of implantation reduced the number of implantation sites (Biggers et al. 1981).
In addition, the concentrations of PGs are elevated in the areas of increased endometrial vascular permeability associated with the initiation of implantation (Kennedy 1977, Evans \& Kennedy 1978, Kennedy \& Zamecnik 1978, Sharma 1979, Lim et al. 1999, Wang et al. 2004b) and exogenous PGs can reverse, at least partially, the effects of indomethacin on implantation (Oettel et al. 1979, Holmes \& Gordashko 1980, Garg \& Chaudhury 1983).

In species in which the application of a deciduogenic stimulus to the sensitized uterus induces decidualization, the extent of the decidual response and the increase in endometrial vascular permeability which precedes it are reduced by indomethacin (reviewed by Kennedy 1990, 1994). Uterine concentrations of PGs are elevated by deciduogenic stimuli before there is a detectable increase in permeability, a time course which is consistent with the elevated levels of PGs being a cause rather than a consequence of the permeability increase. PGs administered into the uterine lumen of animals in which endogenous PG production has been inhibited restore the endometrial responses.

PGs are probably involved not only in the initial vascular changes but also throughout the process of decidualization, as indicated by observations that indomethacin administration $12 \mathrm{~h}$ (Tobert 1976) or up to $48 \mathrm{~h}$ (Kennedy \& Lukash 1982) after the application of a deciduogenic stimulus decreased the extent of decidualization. Because the vascular permeability response to a deciduogenic stimulus occurs by $12 \mathrm{~h}$ (Kennedy 1979, Milligan \& Mirembe 1984), these findings suggest that PGs are also involved in the later stages of the decidual cell reaction. Support for this proposal comes from observations that, while the injection of $\mathrm{PGE}_{2}$ into the uterine lumen of indomethacin-treated rats restored the vascular permeability response to that seen in the absence of inhibition of PG synthesis (Kennedy 1979), decidualization was not restored (Kennedy \& Armstrong 1981). However, the intrauterine infusion of $\mathrm{PGE}_{2}$ restored both the permeability response and the decidualization. The differences in responses to injected and infused PGs suggest that, following injection, the PGs do not remain within the uterus at sufficiently high concentrations long enough to bring about decidualization. Additional indirect evidence that PGs are involved throughout the process of decidualization came from the observation that combined administration of indomethacin, both subcutaneously before a deciduogenic stimulus and intraluminally into the uterine lumen during the decidual cell reaction, resulted in substantially lesser decidualization than either treatment alone (Kennedy 1985). The combined treatment with indomethacin was presumably more effective in inhibiting endometrial PG production in the 5 days during which the decidual reaction occurs than either treatment alone. 


\section{PGs as signaling molecules - the second phase}

The interest in PGs as mediators of the early events in implantation/decidualization waned from around 1985 when investigators concentrated on the roles of locally produced growth factors/cytokines in the processes. However, some investigators explored the possibility that some of the effects of growth factors/cytokines within the endometrium might be a consequence of the modulation of PG production (see, for example, Bany \& Kennedy 1995a, 1995b, 1999). The interest was rekindled when it was reported that female mice with a targeted deletion of Ptgs2 have multiple reproductive deficits, including failure of blastocyst implantation and decidualization (Lim et al. 1997). However, the failure of blastocyst implantation is apparently background specific. Using mice purportedly with the same genetic background, Cheng \& Stewart (2003) found that implantation occurred in these Ptgs2 knockout mice, but that the initial rate of decidual growth after implantation was retarded by $\sim 24 \mathrm{~h}$. One of the possible reasons advanced by Cheng \& Stewart (2003) to explain why their results differed from those of Lim et al. $(1997,1999)$ was the possibility that different breeding protocols may have resulted in the segregation of a critical modifier gene affecting the requirement for PTGS2 during the process of implantation. Subsequently, Wang et al. (2004a) reported that Ptgs2 null mice on a CD-1 background have an improved implantation relative to null mice on a $\mathrm{C} 57 \mathrm{BL} / 6 \mathrm{~J} / 129$ background and this was a consequence of the upregulation of Ptgs1. Despite the differences, all these results are consistent with the notion that PGs are involved in implantation.

Based on the implantation/decidualization phenotype observed in Ptgs2 null mice, it follows that PTGSs should be expressed within the endometrium in the periimplantation period and following artificially induced decidualization. Their expression has been investigated in a number of species, and there are differences between species. In pregnant mice, Ptgs1 expression in the endometrial luminal epithelium is downregulated at the time of blastocyst attachment, while Ptgs2 expression was observed in the luminal epithelium and subepithelial stromal cells at the antimesometrial pole surrounding the blastocyst at this time (Chakraborty et al. 1996). The expression of Ptgs2 was not detected in the interimplantation areas, suggesting that the induction of its expression at the implantation site was induced by the blastocyst. However, it should be noted that the localized increase in endometrial vascular permeability had already occurred at the time these observations were made, and consequently, it cannot be concluded that PTGS2 was responsible for the PGs that resulted in the permeability response. If it could be shown that Ptgs2 expression is increased at implantation sites prior to the increase in permeability, this would provide suggestive evidence that this enzyme might be responsible.
However, for technical reasons related to the difficulty of identifying implantation sites prior to the increase in permeability, no such data exist, and consequently the question of which isoforms of PTGS are involved is unresolved. In pseudopregnant mice, the application of a deciduogenic stimulus to sensitized endometrium induced the expression of Ptgs 2 in the luminal epithelial cells at $2 \mathrm{~h}$ (Lim et al. 1999), followed by a decrease at $8 \mathrm{~h}$ (Lim et al. 1997) and subsequently an expression in the endometrial stroma at $24 \mathrm{~h}$ (Lim et al. 1999). Under these conditions, no changes in Ptgs1 mRNA were observed (Lim et al. 1997). The time course for the changes in Ptgs2 gene expression is consistent with the view that PGs produced by PTGS2 are responsible for the increase in the endometrial vascular permeability that follows the application of a deciduogenic stimulus.

In the rat, PTGS1 immunostaining was reported to be strong in the luminal epithelium at implantation sites on day 6 of pregnancy, with less staining in the interimplantation areas (Cong et al. 2006). PTGS2 was localized to the subepithelial stromal cells on the morning of day 5 before the initiation of implantation, and continued to be expressed in the stroma at both implantation sites and inter-implantation areas through to day 6 . In pseudopregnant rats not given a deciduogenic stimulus, these investigators reported a high level of PTGS1 immunostaining in the luminal epithelium on days 5 and 6 . On day 5 of pseudopregnancy, PTGS2 immunostaining was localized to the antimesometrial subluminal stroma, but this signal was not found on day 6 (Cong et al. 2006). It is not known why the expression of Ptgs2 in the pseudopregnant uterus declined on day 6 , whereas it was maintained in the inter-implantation areas in pregnant rats at the equivalent time. Overall, these results suggest that, in contrast to the mouse, a stimulus provided by the blastocyst or a deciduogenic stimulus is not required in rats for endometrial Ptgs2 expression. Potentially, this might explain why the endometrium of the rat is more sensitive to deciduogenic stimuli than that of the mouse (Finn \& Porter 1975). Furthermore, it explains why uterine PG levels in the rat increase rapidly following the application of a deciduogenic stimulus to sensitized endometrium (Kennedy 1979, 1980a, 1980b, Kennedy et al. 1980).

On day 3 of pregnancy in the hamster, prior to the initiation of implantation, both Ptgs 1 and Ptgs2 mRNA are expressed in the endometrial luminal epithelium (Wang et al. 2004a). During the initiation of implantation on the afternoon of day 4 of pregnancy, Ptgs 1 mRNA expression was decreased in the luminal epithelium at the implantation sites, but not in the inter-implantation areas. By contrast, Ptgs 2 mRNA levels were high in the luminal epithelium and in the subepithelial stroma at implantation sites when compared with the inter-implantation areas. Thus, as in rats, a signal from the blastocyst is not required in hamsters to induce endometrial Ptgs2 expression, 
but the presence of a blastocyst subsequently upregulates Ptgs2 expression.

Endometrial PTGS expression has also been determined during early pregnancy in the ewe (Charpigny et al. 1997, Kim et al. 2003), cow (Emond et al. 2004), sow (Blitek et al. 2006), and mare (Boerboom et al. 2004). With the exception of the mare, pregnancy is associated with the upregulation of PTGS2 gene expression, primarily in the endometrial luminal epithelium. In those studies in which it was investigated, PTGS1 gene expression was reported to be weak (Emond et al. 2004) or unchanged by pregnancy (Charpigny et al. 1997). By contrast, on day 15 of pregnancy in the mare, the presence of the conceptus blocked the induction of PTGS2 expression that was observed on day 15 of the cycle (Boerboom et al. 2004). Presumably, the upregulation of PTGS2 on day 15 of the cycle results in the production of $\mathrm{PGF}_{2 \alpha}$, which is luteolytic, and the inhibition of this upregulation during pregnancy is an anti-luteolytic mechanism.

In the baboon, endometrial PTGS1 expression is decreased in early pregnancy, whereas PTGS2 expression is high at the implantation site, especially in the stromal cells undergoing decidualization (Kim et al. 1999).

\section{Which PG?}

The identity of the PGs involved in the initiation of implantation and decidualization is uncertain. It is possible that different PGs are involved at different times. For example, the endometrial vascular permeability response may be mediated by one PG and another may mediate the subsequent proliferation and differentiation of endometrial stromal cells to decidual cells. In addition, it is possible that there may be differences between species. In attempting to identify the PGs involved, use has been made of uterine PG measurements, responses to exogenously administered PGs, and the assessment of expression of PG receptors within the endometrium.

No single PG has been unequivocally identified as the mediator of endometrial vascular changes as a consequence of PG measurements. Based on the measurements of PG concentrations in implantation sites, there appear to be species-dependent differences. In rats, the concentrations of PGs of the $E, F$, and I series (the latter measured as 6-keto-PGF ${ }_{1 \alpha}$ ) are elevated in implantation sites (Kennedy 1977, Kennedy \& Zamecnik 1978). In the mouse, Pakrasi (1997) reported that PGE concentrations were higher in implantation sites, whereas PGF levels were higher in inter-implantation areas. By contrast, Lim et al. (1999) reported that $\mathrm{PGE}_{2}$ and $\mathrm{PGI}_{2}$ concentrations were higher in implantation sites but found no difference in the $\mathrm{PGF}_{2 \alpha}$ levels. In hamsters, only $\mathrm{PGE}_{2}$ is elevated in implantation sites (Evans \& Kennedy 1978, Wang et al. 2004b). In rabbits, Sharma (1979) reported that the PGE, but not the $\mathrm{PGF}_{2 \alpha,}$ concentrations were higher at implantation sites, whereas Pakrasi \& Dey (1982) found both to be elevated. Following the application of an artificial deciduogenic stimulus, uterine concentration of PGs of the $E, F$, and I series are rapidly increased in the rat (Kennedy 1979, 1980a, 1980 b, Kennedy et al. 1980). For mice, there are varying reports for the effects of deciduogenic stimuli. Jonsson et al. (1979), Rankin et al. (1979) and Milligan \& Lytton (1983) all found the $\mathrm{PGF}_{2 \alpha}$ concentrations to be rapidly increased after stimulation. Jonsson et al. (1979) reported that $\mathrm{PGE}_{2}$ was also increased, while Milligan \& Lytton (1983) found $\mathrm{PGE}_{2}$ as well as $\mathrm{PGI}_{2}$ to be unchanged.

Uterine responses to exogenously administered PGs have been no more enlightening than their measurements. Indirect evidence that $\mathrm{PGF}_{2 \alpha}$ may be involved has come from reports that this PG can induce implantation in rats and mice when given systemically (Saksena et al. 1976, Oettel et al. 1979). However, when administered into the uterine lumen, $\mathrm{PGF}_{2 \alpha}$ was found to be less effective than $\mathrm{PGE}_{2}$ at inducing implantation in mice (Holmes \& Gordashko 1980). More recently, Lim et al. (1999) reported that carbaprostcyclin $\left(\mathrm{CPGI}_{2}\right)$, a stable analog of $\mathrm{PGI}_{2}$, which induces DNA binding and transcriptional activation by PPARD (Forman et al. 1997), is able to induce blastocyst implantation in Ptgs2 null mice when given systemically. Cicaprost, another stable analog of $\mathrm{PGl}_{2}$ that is not a ligand for PPARD, was ineffective. Based on these and other observations, Lim et al. (1999) concluded that $\mathrm{PGI}_{2}$ derived from PTGS2 mediates implantation in the mouse. It is somewhat surprising that the administration of $\mathrm{CPGI}_{2}$ did not induce decidualization in the entire uterus in these studies since the same group had previously reported (Lim et al. 1997) that this compound induced decidualization when given into the uterine lumen (vide infra). Presumably elevated endometrial concentrations of PPARD ligands are by themselves insufficient; an additional stimulus provided by blastocysts or a deciduogenic stimulus is required for decidualization.

Intrauterine administration of $\mathrm{PGF}_{2 \alpha}$ results in decidualization in rats (Sananès et al. 1976) and rabbits (Hoffman et al. 1977) although in the latter study PGE 2 was more effective than $\mathrm{PGF}_{2 \alpha}$. Unfortunately, no inhibitors of endogenous PG production were used in these studies. Consequently, the responses may have been caused by the exogenous PG, endogenously produced PGs, or a combination of exogenous and endogenous PGs. Indeed, subsequent studies by Sananès et al. (1981) revealed that, while $\mathrm{PGF}_{2 \alpha}$ induced decidualization when given to rats in which endogenous PG synthesis was not inhibited, it was ineffective when given to indomethacin-treated animals. In an attempt to circumvent these problems of interpretation, Kennedy \& Lukash (1982) infused PGs into the uterine lumen of rats treated with indomethacin. $\mathrm{PGE}_{2}$ and $\mathrm{PGF}_{2 \alpha}$, alone or 
combined, increased endometrial vascular permeability and produced decidualization. Subsequently, it was shown that when analogs of $\mathrm{PGE}_{2}$ and $\mathrm{PGF}_{2 \alpha}$, which presumably could not be converted to the corresponding F- or E-type analog respectively, were infused, decidualization was only obtained with the E-analog (Kennedy \& Doktorcik 1988). These data were interpreted as suggesting that $\mathrm{PGE}_{2}$ mediates the decidual cell reaction in rats and that the response to $\mathrm{PGF}_{2 \alpha}$ may have involved its conversion within the uterus to $\mathrm{PGE}_{2}$. It should be noted that a complete restoration of decidualization was obtained in indomethacin-treated rats only if the PGs were infused into the uterine lumen. The intrauterine injection of PGs, although effective at restoring the vascular permeability response, did not bring about full decidualization (Kennedy 1979). These results have been interpreted as indicating that PG levels must be elevated within the uterus throughout decidualization, a notion consistent with observations that inhibition of PG synthesis up to $48 \mathrm{~h}$ after the application of a deciduogenic stimulus decreases the extent of decidualization (vide supra). More recently, Lim et al. (1997) reported that the intrauterine injection of $\mathrm{CPGl}_{2}$ was more effective than $\mathrm{PGE}_{2}$ at restoring decidualization in Ptgs2 null mice. However, at best only a partial restoration of decidualization was obtained, possibly because elevated uterine concentrations of PGs were achieved only for a brief period following the injection. Additional evidence that $\mathrm{PGI}_{2}$ may mediate the decidual cell reaction in mice comes from the work of Jonsson et al. (1979), who found that tranylcypromine, purportedly a selective inhibitor of $\mathrm{PGl}_{2}$ synthesis, inhibits decidualization. However, the specificity of this inhibitory action of tranylcypromine has been questioned (Rajtar \& de Gaetano 1979, Buxton \& Murdoch 1982).

In an attempt to identify the PGs involved in the initiation of implantation, investigators have sought to identify the receptors for PGs that are expressed in the endometrium in the peri-implantation period. Binding sites, presumably representing receptors for PGE (Kennedy et al. 1983a), but not for $\mathrm{PGF}_{2 \alpha}$ (Martel et al. 1985), are present in the rat endometrium. In these studies, PGE binding was detected in the endometrial stroma but not in the luminal epithelium of progesterone-treated ovariectomized rats (Kennedy et al. 1983b), whereas in the human binding was localized by autoradiography to stromal cells, glandular epithelium, arterioles, and erythrocytes (Chegini et al. 1986). More recently, Northern blot analyses and in situ hybridization have been used to investigate transcripts for PG receptors in the mouse and the rat uterus. In agreement with the binding studies in rats, in situ hybridization in mice did not detect Ptgfr transcripts in the endometrium on day 4 of pregnancy (Yang et al. 1997). Ptger1 mRNA levels were found to be very low or undetectable in the endometrium of mice (Katsuyama et al. 1997) and rats (Papay \& Kennedy 2000) in the peri-implantation period.
By contrast, mRNA expression of Ptger2, Ptger3, and Ptger 4 was cell specific and correlated with endometrial preparation for implantation and decidualization in both mice (Yang et al. 1997) and rats (Papay \& Kennedy 2000). For both mice and rats, Ptger2 transcripts were localized to the luminal epithelium, whereas Ptger4 transcripts were localized to both the luminal epithelium and the stroma in mice but were restricted to the subepithelial stroma in rats. Ptger3 transcripts were localized to the glandular epithelium and subepithelial stroma of rats and to stromal cells at the mesometrial pole in mice. The failure to detect PGE-binding sites in membrane preparations from rat epithelial cells contrasts with the detection of Ptger2 transcripts in these cells. This apparent discrepancy is almost certainly a consequence of the fact that the binding studies were performed on the luminal epithelium of progesterone-treated ovariectomized rats. Ptger2 transcripts were detected in luminal epithelium only after the administration of estradiol to progesterone-treated rats (Papay \& Kennedy 2000). It is intriguing that, in the rat, transcripts for Ptger2 and Ptger4 are concentrated in the antimesometrial pole of the uterus on the equivalent of day 5 of pseudopregnancy when the endometrium is sensitized for the decidual cell reaction (Papay \& Kennedy 2000). The localization of these receptors could facilitate the initiation of decidualization, which begins in the antimesometrial region. However, it must be noted that mice deficient in each Ptger subtype have been generated and an implantation/decidualization phenotype has not been reported (see Sugimoto \& Narumiya 2007), suggesting that these receptors are not essential for implantation/decidualization.

In the mouse, Ptgir mRNA levels are very low to undetectable in the uterus in the peri-implantation period (Lim et al. 1999), suggesting that this receptor is not critical for implantation and decidualization. In support of this conclusion is the fact that Ptgir null female mice are fertile (Murata et al. 1997). Ppard expression is undetectable in the mouse uterus prior to implantation but is upregulated in the stroma at implantation sites late on day 4 of pregnancy (Lim et al. 1999). This upregulation was detected after the increase in endometrial vascular permeability had occurred. If PPARD is to mediate this early event in implantation, then it should be expressed prior to the increase in endometrial vascular permeability. The study by Lim et al. (1999) does not provide information on this. However, Scherle et al. (2000) determined Ppard expression in the uterus of pseudopregnant mice 2, 8, and $24 \mathrm{~h}$ after a deciduogenic stimulus. Ppard expression was observed at $24 \mathrm{~h}$ but not at the earlier times. Since the endometrial vascular permeability increase is detectable within $4 \mathrm{~h}$ of a deciduogenic stimulus, it seems unlikely that PPARD mediates this early event in decidualization. It should be noted that $\mathrm{PGI}_{2}$ itself has never been shown to be a ligand for PPARD, only that some stable analogs of $\mathrm{PGl}_{2}$ are ligands. Furthermore, it is noteworthy that Ppard null 


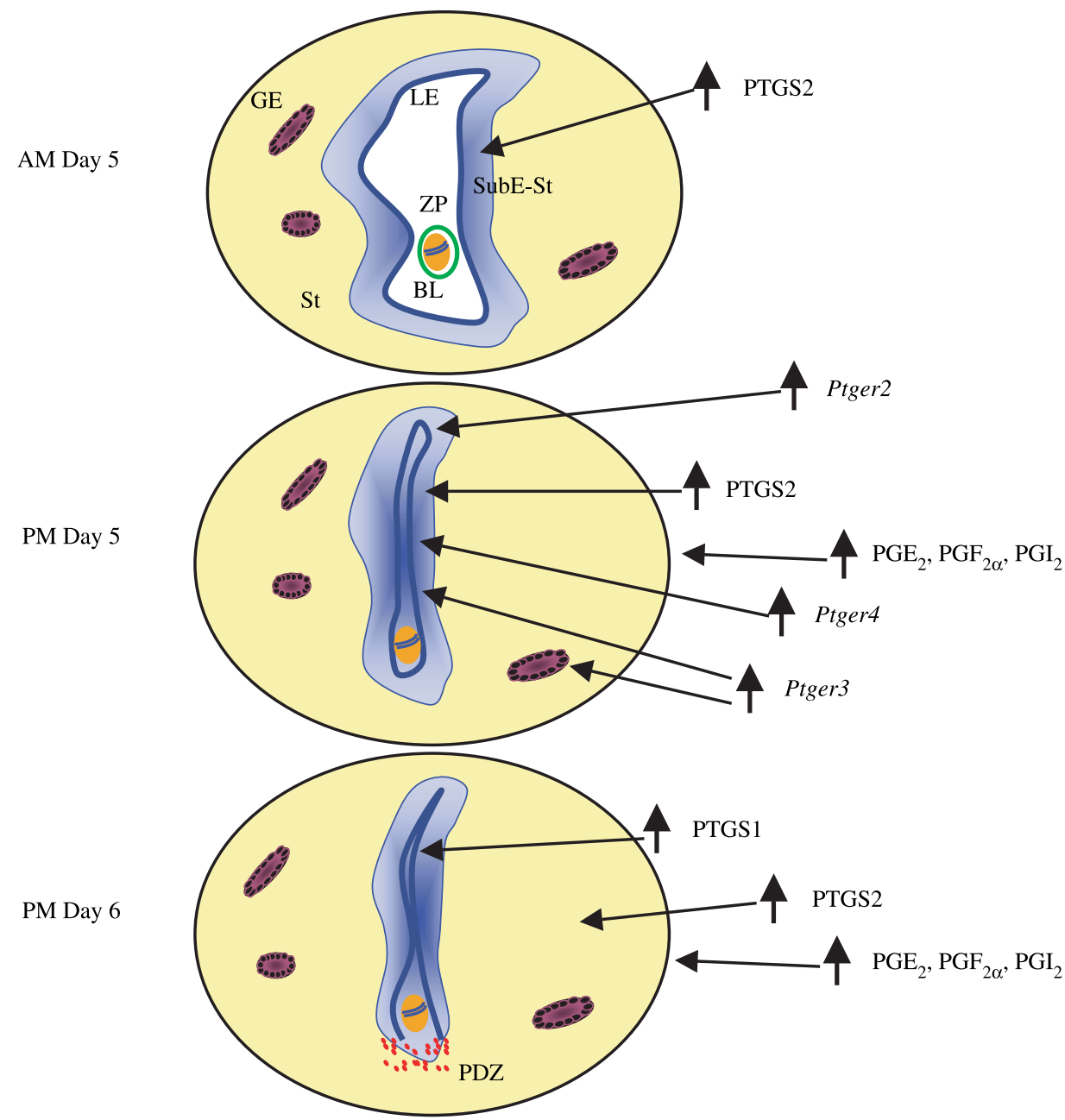

Figure 2 Schematic representation of changes in expression of genes involved in prostaglandin (PG) synthesis and action at implantation sites in rat endometrium on days 5-6 of pregnancy. BL, blastocyst; GE, glandular epithelium; LE, luminal epithelium; PTGS, prostaglandinendoperoxide synthase; Ptger, prostaglandin E receptor; PDZ, primary decidual zone; St, stroma; SubE-St, sub-epithelia-stroma; ZP, zona pellucida.

mice have been independently generated by three laboratories (Peters et al. 2000, Barak et al. 2002, Nadra et al. 2006). All laboratories reported that breeding heterozygous mice resulted in fewer null mice than expected, but significantly all groups reported that the null females were fertile although Nadra et al. (2006) found that the litter size produced by null females was lower than control heterozygous mating. Overall, these results raise doubts about the involvement of PPARD in the early events of implantation/decidualization.

\section{Concluding comments}

Changes in the expression of genes involved in PG synthesis and action within the peri-implantation endometrium, with particular reference to the rat, are summarized in Fig. 2. While there are extensive data indicating that PGs have an important role in implantation/decidualization in many species, there are still numerous gaps in our knowledge. In particular, the type(s) of PGs involved has not been definitively established. There may be species differences, and different PGs may be involved in different processes. Finally, given that implantation is such a crucial event, there may well be redundancy in the system.

\section{Acknowledgements}

The authors thank Elizabeth Ross for her assistance in preparing the manuscript. The research performed in TGK's laboratory was supported by grants from the Canadian Institutes of Health Research. This review is based on a lecture presented by TGK at the 52nd Annual Meeting of the Canadian Fertility and Andrology Society in Ottawa, Canada on 17 November 2006. The authors declare that there is no conflict of interest that would prejudice the impartiality of this scientific work. 


\section{References}

Bany BM \& Kennedy TG 1995 a Interleukin-1 $\alpha$ regulates prostaglandin production and cyclooxygenase activity in sensitized rat endometrial stromal cells in vitro. Biology of Reproduction 53 126-132.

Bany BM \& Kennedy TG $1995 b$ Regulation by epidermal growth factor of prostaglandin production and cyclooxygenase activity in sensitized rat endometrial stromal cells in vitro. Journal of Reproduction and Fertility $10457-62$.

Bany BM \& Kennedy TG 1999 Role of interleukin-1 in the regulation of cyclooxygenase gene expression in rat endometrial stromal cells. Journal of Reproduction and Fertility 115 125-131.

Barak Y, Liao D, He W, Ong ES, Nelson MC, Olefsky JM, Boland R \& Evans RM 2002 Effects on peroxisome proliferator-activated receptor $\delta$ on placentation, adiposity, and colorectal cancer. PNAS 99 303-308.

Biggers JD, Baskar JF \& Torchiana DF 1981 Reduction of fertility of mice by the intrauterine injection of prostaglandin antagonists. Journal of Reproduction and Fertility 63 365-372.

Bitton-Casimiri V, Brun JL \& Psychoyos A 1970 Comportement in vitro des blastocysts du 5 e jour de la gestation chez la ratte. Etude microcinematographique. Comptes Rendus Hebdomadaires des Séances de I'Académie des Sciences. Série D: Sciences Naturelles 270 2979-2982.

Blitek A, Waclawik A, Kaczmarek MM, Stadjek T, Pejsak Z \& Ziecik AJ 2006 Expression of cyclooxygenase- 1 and -2 in the porcine endometrium during the oestrous cycle and early pregnancy. Reproduction in Domestic Animals 41 251-257.

Boerboom D, Brown KA, Vaillancourt D, Poitras P, Goff AK, Watanabe K, Dore M \& Sirois J 2004 Expression of key prostaglandin synthases in equine endometrium during late diestrus and early pregnancy. Biology of Reproduction 70 391-399.

Buxton LE \& Murdoch RN 1982 Lectins, calcium ionophore A23187 and peanut oil as deciduogenic agents in the uterus of pseudopregnant mice: effects of tranylcypromine. indomethacin, iproniazid and propanolol. Australian Journal of Biological Sciences 35 63-72.

Chakraborty I, Das SK, Wang J \& Dey SK 1996 Developmental expression of the cyclo-oxygenase- 1 and cyclo-oxygenase-2 genes in the periimplantation mouse uterus and their differential regulation by the blastocyst and ovarian steroids. Journal of Molecular Endocrinology 16 107-112.

Charpigny G, Reinaud P, Tamby JP, Creminon C, Martal J, Maclouf J \& Guillomot M 1997 Expression of cyclooxygenase-1 and -2 in ovine endometrium during the estrous cycle and early pregnancy. Endocrinology 138 2163-2171.

Chegini N, Rao CV, Wakim N \& Sanfilippo J 1986 Prostaglandin binding to different cell types of human uterus: quantitative light microscope autoradiographic study. Prostaglandins, Leukotrienes, and Essential Fatty Acids 22 129-138.

Cheng JG \& Stewart CL 2003 Loss of cyclooxygenase-2 retards decidual growth but does not inhibit embryo implantation or development to term. Biology of Reproduction 68 401-404.

Cole RJ 1967 Cinemicrographic observations on the trophoblast and zona pellucida of the mouse blastocyst. Journal of Embryology and Experimental Morphology 17 481-490.

Cong J, Diao H-L, Zhao Y-C, Ni H, Yan Y-Q \& Yang Z-M 2006 Differential expression and regulation of cylooxygenases[sic], prostaglandin $\mathrm{E}$ synthases and prostacyclin synthase in rat uterus during the periimplantation period. Reproduction 131 139-151.

Dey SK, Lim H, Das SK, Reese J, Paria BC, Daikoku T \& Wang H 2004 Molecular cues to implantation. Endocrine Reviews 25 341-373.

Emond V, MacLaren LA, Kimmins S, Arosh JA, Fortier MA \& Lambert RD 2004 Expression of cyclooxygenase-2 and granulocyte-macrophage colony-stimulating factor in the endometrial epithelium of the cow is up-regulated during early pregnancy and in response to intrauterine infusions of interferon- $\tau$. Biology of Reproduction 70 54-64.

Enders AC \& Schlafke S 1979 Comparative aspects of blastocystendometrial interactions at implantation. Ciba Foundation Symposia $643-32$.

Evans CA \& Kennedy TG 1978 The importance of prostaglandin synthesis for the initiation of blastocyst implantation in the hamster. Journal of Reproduction and Fertility 54 255-261.

Ferrando G \& Nalbandov AV 1968 Relative importance of histamine and estrogen on implantation in rats. Endocrinology 83 933-937.
Finn CA \& Porter DG 1975 The Uterus, Acton: Publishing Sciences Group.

Forman BM, Chen J \& Evans RM 1997 Hypolipidemic drugs, polyunsaturated fatty acids, and eicosanoids are ligands for peroxisome proliferatoractivated receptors $\alpha$ and $\delta$. PNAS 94 4312-4317.

Garg SK \& Chaudhury RR 1983 Evidence for a possible role of prostaglandins in implantation in rats. Archives Internationales de Pharmacodynamie et de Thérapie 262 299-307.

Hedlund K, Nilsson O, Reinius S \& Aman G 1972 Attachment reaction of the uterine luminal epithelium at implantation: light and electron microscopy of the hamster, guinea-pig, rabbit and mink. Journal of Reproduction and Fertility 29 131-132.

Hoffman LH, Strong GB, Davenport GR \& Frölich JC 1977 Deciduogenic effect of prostaglandins in the pseudopregnant rabbit. Journal of Reproduction and Fertility 50 231-237.

Holmes PV \& Gordashko BJ 1980 Evidence for prostaglandin involvement in blastocyst implantation. Journal of Embryology and Experimental Morphology 55 109-122.

Horan AH 1971 The suppression of inflammatory edema at the nidation site by sodium salicylate and nitrogen mustard in the rat. Fertility and Sterility 22 392-397.

Hurst PR \& MacFarlane DW 1981 Further effects of nonsteroidal antiinflammatory compounds on blastocyst hatching in vitro and implantation rates in the mouse. Biology of Reproduction 25 777-784.

Jonsson HT Jr, Rankin JC, Ledford BE \& Baggett B 1979 Uterine prostaglandin levels following stimulation of the decidual cell reaction: effects of indomethacin and tranylcypromine. Prostaglandins 18 847-857.

Katsuyama M, Sugimoto $Y$, Morimoto K, Hasumoto K, Fukumoto $M$, Negishi M \& Ichikawa A 1997 Distinct cellular localization of the messenger ribonucleic acid for prostaglandin E receptor subtypes in the mouse uterus during pseudopregnancy. Endocrinology 138 344-350.

Kennedy TG 1977 Evidence for a role for prostaglandins in the initiation of blastocyst implantation in the rat. Biology of Reproduction 16 286-291.

Kennedy TG 1979 Prostaglandins and increased endometrial vascular permeability resulting from the application of an artificial stimulus to the uterus of the rat sensitized for the decidual cell reaction. Biology of Reproduction 20 560-566.

Kennedy TG 1980a Estrogen and uterine sensitization for the decidual cell reaction: role of prostaglandins. Biology of Reproduction 23 955-962.

Kennedy TG $1980 b$ Timing of uterine sensitivity for the decidual cell reaction: role of prostaglandins. Biology of Reproduction 22 519-525.

Kennedy TG 1985 Evidence for the involvement of prostaglandins throughout the decidual cell reaction in the rat. Biology of Reproduction 33 140-146.

Kennedy TG 1990 Eicosanoids and blastocyst implantation. In Eicosanoids in Reproduction, pp 123-138. Ed. MD Mitchell. Boca Raton: CRC Press.

Kennedy TG 1994 Involvement of local mediators in blastocyst implantation. In Endocrinology of Embryo-Endometrial Interactions, Eds SR Glasser, J Mulholland \& A Psychoyos. New York: Plenum.

Kennedy TG 2003 Decidualization. In Encyclopedia of Hormones, pp 379-385. Eds HL Henry \& AW Norman. San Diego: Elsevier.

Kennedy TG \& Armstrong DT 1981 The role of prostaglandins in endometrial vascular changes at implantation. In Cellular and Molecular Aspects of Implantation, pp 349-363. Eds SR Glasser \& DW Bullock. New York: Plenum.

Kennedy TG \& Doktorcik PE 1988 Effects of analogues of prostaglandin $E_{2}$ and $F_{2 \alpha}$ on the decidual cell reaction in the rat. Prostaglandins $\mathbf{3 5}$ 207-219.

Kennedy TG \& Lukash LA 1982 Induction of decidualization in rats by the intrauterine infusion of prostaglandins. Biology of Reproduction 27 253-260.

Kennedy TG \& Zamecnik J 1978 The concentration of 6-keto-prostaglandin $\mathrm{F}_{1 \alpha}$ is markedly elevated at the site of blastocyst implantation in the rat. Prostaglandins 16 599-605.

Kennedy TG, Barbe GJ \& Evans CA 1980 Prostaglandin $I_{2}$ and increased endometrial vascular permeability preceding the decidual cell reaction. In The Endometrium, pp 331-344. Ed. FA Kimball. New York: Spectrum.

Kennedy TG, Martel D \& Psychoyos A 1983a Endometrial prostaglandin $E_{2}$ binding: characterization in rats sensitized for the decidual cell reaction and changes during pseudopregnancy. Biology of Reproduction 29 556-564. 
Kennedy TG, Martel D \& Psychoyos A 1983 b Endometrial prostaglandin $E_{2}$ binding during the estrous cycle and its hormonal control in ovariectomized rats. Biology of Reproduction 29 565-571.

Kim JJ, Wang J, Bambra C, Das SK, Dey SK \& Fazleabas AT 1999 Expression of cyclooxygenase- 1 and -2 in the baboon endometrium during the menstrual cycle and pregnancy. Endocrinology 140 2672-2678.

Kim S, Choi Y, Spencer TE \& Bazer FW 2003 Effects of the estrous cycle, pregnancy and interferon $\tau$ on expression of cyclooxygenase two (COX-2) in ovine endometrium. Reproductive Biology and Endocrinology 158 (http://www.RBEj.com/content/1/1/58).

Lejeune B, VanHoeck J \& Leroy F 1981 Transmitter role of the luminal uterine epithelium in the induction of decidualization in rats. Journal of Reproduction and Fertility 61 235-240.

Lim H, Paria BC, Das SK, Dinchuk JE, Lagenbach R, Trzaskos JM \& Dey SK 1997 Multiple female reproductive failures in cyclooxygenase 2-deficient mice. Cell 91 197-208.

Lim H, Gupta RA, Ma W, Paria BC, Moller DE, Morrow JD, DuBois RN, Trzaskos JM \& Dey SK 1999 Cyclo-oxygenase-2-derived prostacyclin mediates embryo implantation in the mouse via PPAR $\delta$. Genes and Development 13 1561-1574.

Ljungkvist I 1972 Attachment reaction of rat uterine luminal epithelium. IV. The cellular changes in the attachment reaction and its hormonal regulation. Fertility and Sterility 23 847-865.

Martel D, Kennedy TG, Monier MN \& Psychoyos A 1985 Failure to detect specific binding sites for prostaglandin $F_{2 \alpha}$ in membrane preparations from rat endometrium. Journal of Reproduction and Fertility 75 265-274.

Martin L, Finn CA \& Carter J 1970 Effects of progesterone and oestradiol on the luminal epithelium of the mouse uterus. Journal of Reproduction and Fertility 21 461-469.

Milligan SR \& Lytton FDC 1983 Changes in prostaglandin levels in the sensitized and non-sensitized uterus on the mouse after the intrauterine instillation of oil or saline. Journal of Reproduction and Fertility $\mathbf{6 7}$ 373-377.

Milligan SR \& Mirembe FM 1984 Time course of the changes in uterine vascular permeability associated with the development of the decidual cell reaction in ovariectomized steroid-treated rats. Journal of Reproduction and Fertility 70 1-6.

Murata T, Ushikubi F, Matsuoka T, Hirata M, Yamasaki A, Sugimoto $Y$, Ichikawa A, Aze Y, Tanaka T, Yoshida N et al. 1997 Altered pain perception and inflammatory response in mice lacking prostacyclin receptor. Nature 388 678-682.

Nadra K, Anghel SI, Joye E, Tan NS, Basu-Modak S, Trono D, Wahli W \& Desvergne B 2006 Differentiation of trophoblast giant cells and their metabolic functions are dependent on peroxisome proliferator-activated receptor $\beta / \delta$. Molecular and Cellular Biology 26 3266-3281.

Oettel M, Koch M, Kurischko A \& Schubert K 1979 A direct evidence for the involvement of prostaglandin $F_{2 \alpha}$ in the first step of estrone-induced blastocyst implantation in the spayed rat. Steroids $331-8$.

Pakrasi PL 1997 Prostaglandins and ovum implantation in mice. Journal of Experimental Zoology 278 53-57.

Pakrasi PL \& Dey SK 1982 Blastocyst is the source of prostaglandins in the implantation site in the rabbit. Prostaglandins 24 73-77.

Papay KD \& Kennedy TG 2000 Characterization of temporal and cellspecific changes in transcripts for prostaglandin $E_{2}$ receptors in pseudopregnant rat endometrium. Biology of Reproduction 62 $1515-1525$.

Paria BC, Reese J, Das SK \& Dey SK 2002 Deciphering the cross-talk of implantation: advances and challenges. Science 296 2185-2188.
Parkening TA 1976 An ultrastructural study of implantation in the golden hamster. I. Loss of the zona pellucida and initial attachment to the uterine epithelium. Journal of Anatomy 121 161-184.

Peters JM, Lee SST, Li W, Ward JM, Gavrilova O, Everett C, Reitman ML, Hudson LD \& Gonzalez FJ 2000 Growth, adipose, brain, and skin alterations resulting from targeted disruption of the mouse peroxisome proliferator-activated receptor $\beta(\delta)$. Molecular and Cellular Biology 20 $5119-5128$.

Psychoyos A 1973 In Handbook of Physiology, section 7, vol II, part 2, pp 187-215. Eds RO Greep, EB Astwood \& SR Geiger. Bethesda: American Physiological Society.

Rajtar G \& deGaetano G 1979 Tranylcypromine is not a selective inhibitor of prostacyclin in rats. Thrombosis Research 14 245-248.

Rankin JC, Ledford BE, Jonsson HT \& Baggett B 1979 Prostaglandins, indomethacin and the decidual cell reaction in the mouse uterus. Biology of Reproduction 20 399-404.

Saksena SK, Lau IF \& Chang MC 1976 Relationship between oestrogen, prostaglandin $\mathrm{F}_{2 \alpha}$ and histamine in delayed implantation in the mouse. Acta Endocrinologica 81 801-807.

Sananès N, Baulieu E-E \& Le Goascogne C 1976 Prostaglandin(s) as inductive factor of decidualization in the rat uterus. Molecular and Cellular Endocrinology 6 153-158.

Sananès N, Baulieu E-E \& Le Goascogne C 1981 A role for prostaglandins in decidualization of the rat uterus. Journal of Endocrinology 89 25-33.

Scherle PA, Ma W, Lim H, Dey SK \& Trzaskos JM 2000 Regulation of cyclooxygenase-2 induction in the mouse uterus during decidualization. Journal of Biological Chemistry 275 37086-37092.

Segalen J \& Chambon Y 1983 Ultrastructural aspects of the antimesometrial implantation in the rabbit. Acta Anatomica 115 1-7.

Sharma SC 1979 Temporal changes in PGE, PGF ${ }_{\alpha,}$ oestradiol $17 \beta$ and progesterone in uterine venous plasma and endometrium of rabbits. INSERM Symposium 91 243-264.

Simmons DL, Botting RM \& Hla T 2004 Cyclooxygenase isozymes: the biology of prostaglandin synthesis and inhibition. Pharmacological Reviews 56 387-437.

Sugimoto Y \& Narumiya S 2007 Prostaglandin E receptors. Journal of Biological Chemistry 282 11613-11617.

Tobert JA 1976 A study of the possible role of prostaglandins in decidualization using a nonsurgical method for the instillation of fluids into the rat uterine lumen. Journal of Reproduction and Fertility $\mathbf{4 7}$ 391-393.

Wang H, Ma W, Tejada L, Zhang H, Morrow JD, Das SK \& Dey SK 2004 a Rescue of female infertility from the loss of cyclooxygenase-2 by compensatory up-regulation of cyclooxygenase- 1 is a function of genetic makeup. Journal of Biological Chemistry 279 10649-10658.

Wang X, Su Y, Deb K, Raposo M, Morrow JD, Reese J \& Paria BC $2004 b$ Prostaglandin $E_{2}$ is a product of induced prostaglandin-endoperoxide synthase 2 and microsomal-type prostaglandin $E$ synthase at the implantation site of the hamster. Journal of Biological Chemistry 279 30579-30587.

Yang ZM, Das SK, Wang J, Sugimoto Y, Ichikawa A \& Dey SK 1997 Potential sites of prostaglandin actions in the periimplantation mouse uterus: different expression and regulation of prostaglandin receptor genes. Biology of Reproduction 56 368-379.

Received 17 July 2007

First decision 24 August 2007

Accepted 7 September 2007 